\title{
Comparison analysis of induction and line-start synchronous reluctance motors
}

\author{
Mateusz Grycmacher ${ }^{1}$, Wieslaw Lyskawinski ${ }^{1}$, Wojciech Szelag ${ }^{1}$ \\ ${ }^{1}$ Poznan University of Technology, Institute of Electrical Engineering and Electronics, Piotrowo 3A, 60-965 Poznan, Poland
}

\begin{abstract}
The article presents research on the development of a low-cost line start synchronous reluctance motor (LSSRM) on the basis of components of a mass-produced three-phase low-power cage induction motor (IM). The aim was to obtain the best functional parameters for both the steady-state work condition and the asynchronous start-up. In the design-optimization calculations of the LSSRM, a field model of electromagnetic phenomena developed using the MagNet program was used. Laboratory tests were carried out on the designed and constructed prototype of the LSSRM, and the obtained results were compared with the results of an IM test.
\end{abstract}

\section{Introduction}

The need to develop low-cost and reliable low-power electric drive systems operating at a constant rotational speed prompted the authors to undertake research on LSSRMs adapted for direct start-up. When designing such type of motors, similar in design to line start permanent magnet synchronous motors[1-4], besides meeting the requirements of parameters for steady-state operation, additional requirements related to asynchronous operation, regarding minimum starting torque, stalling torque and fall into step, should be met.

Due to the complex course of electromagnetic phenomena in electric machines, non-linearity of the magnetic circuit, induced eddy currents and the required high reliability of calculations for the analysis of operating states and motor design, a field model and the finite element method were used. This approach was used to simulate the operating conditions of the IM as well as LSSRM. The numerical models of both motors were developed using the MagNet software.

\section{Simulation tests}

First, the transients as well as the steady states of an IM Sh71-4A type were analyzed. The selected results of the calculation, referring only to the start-up process at the rated load $\left(T_{N}=1.73 \mathrm{Nm}\right)$, are shown in Fig. 1. The high concordance of the simulation and experimental results of the IM tests indicates the purposefulness of using the field approach for the analysis and design of an LSSRM as well.

The parameterized numerical models $\mathrm{W} 1$ and W2 were developed for two variants of the reluctance motor rotor (Fig. 2). These models were used to analyze the influence of the angular extent $\alpha$ and the depth $h$ of the cut-out on the maximum $T_{m}$ of the reluctance torque and over the course of the start-up process. The torque $T_{m}$ was determined on the basis of the calculated dependence $T(\vartheta)$ of the electromagnetic torque $T$ on the angular position of the rotor $\vartheta$ (Fig. 3a). It was assumed that the RMS value of the current in the windings is equal to the rated current $I_{N}$ of the IM.
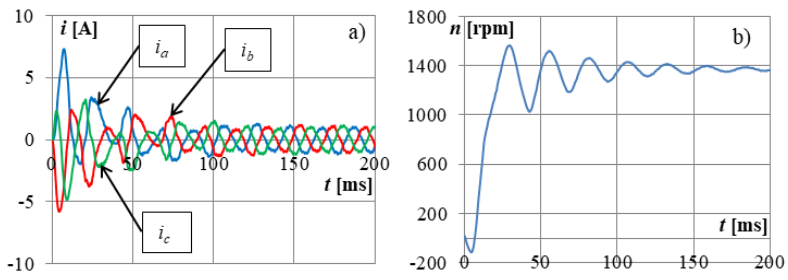

Fig. 1.The waveforms of the phase currents (a) and the rotational speed $n$ (b) during the start-up of the IM.
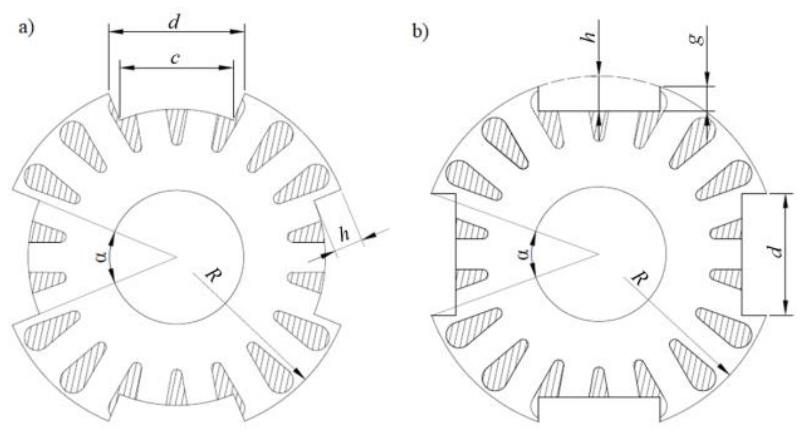

Fig. 2. Rotor of the reluctance motor (a) with an arc cut - W1 and (b) with a flat cut - W2.

In order to determine the value of the angle $\alpha$ and the depth $h$ of the cut-out, for which the largest torque $T_{m}$ is obtained for both considered rotor structures, optimization calculations were carried out. A systematic review method was used in the optimization process. The article contains only the characteristics $T_{m}(\alpha)$ for $h=$ const (Fig. 3 b). In order to shorten the calculation 
process, the time-consuming analysis of the LSSRM start-up was initiated only after the optimization calculations for the optimal parameter values $(\alpha, h)_{\text {opt }}$ were completed.
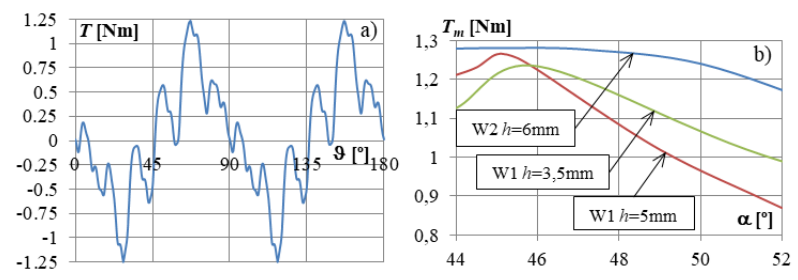

Fig. 3. Characteristics $T(\vartheta)$ (a) and dependence $T_{m}(\alpha)(\mathrm{b})$.

The calculations performed for the $T_{o}=1 \mathrm{Nm}$ load confirmed the starting capacity of the motors. The examples of the $n(t)$ waveforms for the start-up of the motor with the W1 rotor are shown in Fig. 4.

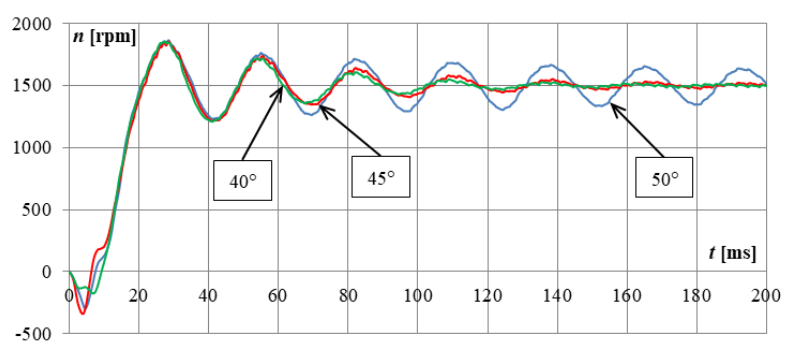

Fig. 4. Waveforms $n(t)$ for W1 rotor; $\alpha=$ const and $h=5 \mathrm{~mm}$.

\section{Experimental research}

The IM and LSSRM prototype tests were carried out on the measuring stand shown in Fig. 5. The determined mechanical characteristics $n(T)$ of the IM and the torqueangle $T(\beta)$ characteristics of the LSSRM are shown in Fig. 6. The measurements were made for a range of load torque $T_{o}$ changes, for which the phase current $I \leq I_{N}$. In addition, Fig. $6 \mathrm{~b}$ shows the torque-angle characteristics $T(\beta)$ determined from the classical dependence on the reluctance torque [5]

$$
T=\frac{3}{2 \omega_{s}} U^{2}\left(\frac{1}{X_{q}}-\frac{1}{X_{d}}\right) \sin 2 \beta
$$

where: $\omega_{s}$ is the synchronous angular speed, $\beta$ is the power angle.

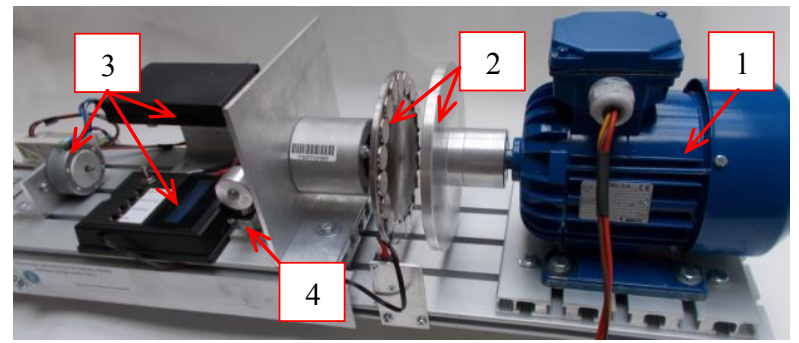

Fig. 5. Test stand; 1 - motor, 2 - eddy-current brake, 3 - control-measuring system, 4 - torque-meter.

Synchronous reactances $X_{d}$ and $X_{q}$ were determined based on measurements and utilization of the Clark and
Park transformations [6]. The efficiency $\eta$ and the power factor $\cos \varphi$ characteristics of both motors, obtained from the measurement at the supply voltage $U=$ const, are shown in Fig. 7.
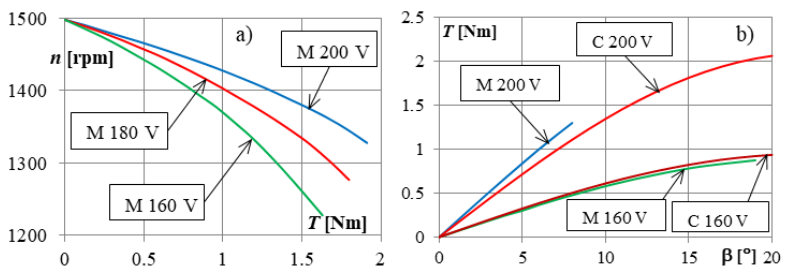

Fig. 6. Characteristics: (a) $n(T)$ of IM and (b) $T(\beta)$ of LSSRM from calculations $(\mathrm{C})$ and measurements $(\mathrm{M})$.

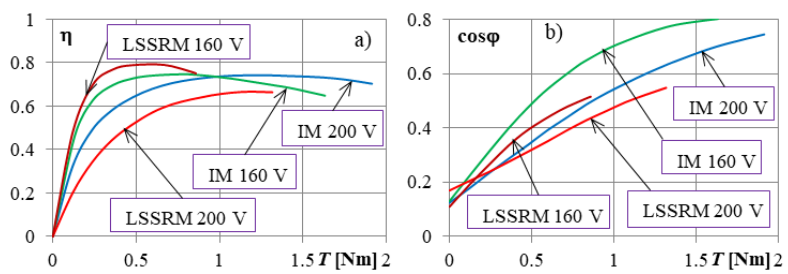

Fig. 7. Efficiency (a) and power factors (b) of IM and LSSRM for $U=$ const.

\section{Conclusions}

The performed tests, based on the components of massproduced induction motors, have confirmed that, it is possible to develop and implement the production of very cheap line start reluctance synchronous motors with good functional parameters. On the basis of the comparative analysis of both types of motors operating in a wide range of load torque changes, it can be stated that the functional parameters of the reluctance motor are slightly worse than the inductive ones. However, when it comes to low load torque at a reduced supply voltage, the efficiency of the reluctance motor can be greater than the efficiency of the induction motor. It is therefore, advisable to carry out further intensive design and optimization work on the development of an improved line start reluctance rotor structure and its functional parameters.

\section{References}

1. M. Barański, W. Szelag, C. Jedryczka, IEEE Xplore (2017), DOI: 10.1109/ISEM.2017.7993535

2. C. Jędryczka, Ł. Knypiński, A. Demenko, J. K. Sykulski, IEEE Trans. Mag., 54, (2017), DOI: 10.1109/TMAG.2017.2764680

3. Ł. Knypiński, L. Nowak, C. Jędryczka, COMPEL, 34, 882, (2015)

4. W. Łyskawiński, C. Jędryczka, W. Szeląg, IEEE (2017), DOI: 10.1109/ISEM.2017.7993556

5. M. Šebest, V.Hrabovcová, P.Makyš, IEEE (2016), DOI: 10.1109/ELEKTRO.2016.7512100

6. P. Krause, O. Wasynczuk, S. Sudhoff, S. Pekarek, IEEE Press Wiley (2013) 